Germanistische Abhandlungen 


\section{Die Erzählung im Sturm und Drang}

Studien zur Prosa des achtzehnten Jahrhunderts 


\section{GERMANISTISCHE ABHANDLUNGEN 66}

CIP-Titelaufnahme der Deutschen Bibliothek

Dedert, Hartmut:

Die Erzählung im Sturm und Drang : Studien zur Prosa des achtzehnten Jahrhunderts / Hartmut Dedert. - Stuttgart :

Metzler, 1990

(Germanistische Abhandlungen ; 66)

NE: GT

ISBN 978-3-476-00722-3

ISBN 978-3-476-03332-1 (eBook)

DOI 10.1007/978-3-476-03332-1

Dieses Werk einschließlich aller seiner Teile ist urheberrechtlich geschützt. Jede Verwertung außerhalb der engen Grenzen des Urheberrechtsgesetzes ist ohne Zustimmung des Verlages unzulässig und strafbar. Das gilt insbesondere für Vervielfältigungen, Übersetzungen, Mikroverfilmungen und die Einspeicherung und Verarbeitung in elektronischen Systemen.

(C) 1990 Springer-Verlag GmbH Deutschland Ursprünglich erschienen bei J.B. Metzlersche Verlagsbuchhandlung und Carl Ernst Poeschel Verlag GmbH in Stuttgart 1990 
1 Forschungsstand und Vorgehensweise . . . . . . . . . . . . 1

2 Traditionen und Tendenzen . . . . . . . . . . . . . . 7

Erzäblen im Sturm und Drang-ein tour d'borizon . . . . . . . . . . . . 7

Matthias Claudius: Wandsbecker Botschaften von nah und fern . . . . . . . . 13

Johann Heinrich Jung (Stilling): Erbaunng im Zeichen der Providen₹ . . . . 17

Christian Friedrich Daniel Schubart: Aufklärung und Parteinabme . . . . . 20

Jobann Heinrich Merck: Zeit- und Sittenbilder aus dem deutschen Alltagsleben . 24

Friedrich (Maler) Müller: Die Humanität der Idylle . . . . . . . . . . . . . 29

3 Jakob Michael Reinhold Lenz: Kritik und Konstruktion . . . . 36

Tief auf den kalten Nesseln meines Schicksals - Beobachtungen qu einem geniezeitlichen Emanzipationsversuch . . . . . . . . . . . . . 36

Zerbin oder die neuere Philosopbie . . . . . . . . . . . . . . . .

Literarisches Programm und Exposition 39 - Liebe zwischen Galanterie und Versorgungsdenken 41 - Das Opfer einer so unredlichen Politik 43 - Der Leidensweg der Heiligen Marie 46 - Vom Luftschloß in den Stadtgraben 50 - In Marmontels Manier, aber nicht mit seinem Pinsel 55

Der Landprediger . . . . . . . . . . . . . . . . . . .

Johannes Mannheim - ein literarisches Wunschbild 61 - Der Prediger als Populärphilosoph 62 - Der Schüler der Neologie 63 - Der Intellektuelle als Musterbauer 65 Konfrontation mit dem städtischen Bürgertum 69-Maßvoll regulierte Leidenschaft als empfindsames Modell wirklicher Liebe 71 - Konfrontation mit dem Adel 74 - Haus und Familie als Ort bürgerlicher Selbstverwirklichung 77 - Literaturkritik vom 'Standpunkt des Maßes und der Mitte als Kritik an >Romanhaftigkeit und sunnatürlicher Empfindsamkeit 79 - Dialektik des Totenkultes: Ritualisiertes Andenken und verlorenes Gedächtnis - Negation von Gegenwart und Rückbesinnung auf verlorene Vergangenheit 85 - Anmerkungen zur Praxis des Erzählens 90 
4 Anton Matimias Sprickmann: Die Hexe Liebeein Thema mit Variationen . . . . . . . . . . . . . .

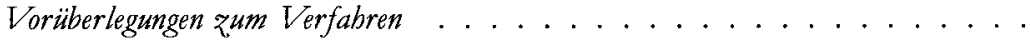

Nachrichten aus Amerika ...................

Der Held und seine Familie 96 - Das Idealbild vom Kaufmann 101 - Liebe zwischen platonischem Mythos und bürgerlichem Sexualtabu 105 - Leidenschaft und Moral im Konflikt zwischen Mutter und Sohn 111 - Die nachgeholte Vorgeschichte - Gründe und Hintergründe der rätselhaften Ereignisse 116 - Die Logik des Konfliktes und seiner Lösung 120 - Neue Welt, neue Gefühle, neue Zukunft - über die historische Aktualität eines Traums 123

Variationen eines Themas - Sprickmanns übrige Liebesgeschichten . . . . . . . .

Die Untreu aus Zärtlichkeit. Eine Konversation und ein Brief 132 - Das Intelligenzblatt, eine Erzählung 136 - Das Neujahrsgeschenk. Eine Klosteranekdote 138-Das Wort zur rechten Zeit. Eine Erzählung 140 - Mariens Reden bei ihrer Trauung. Ein Fragment 141

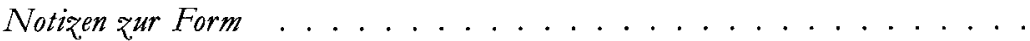

Dramatischer Aufbau 143 - Dialog und Szene 145 - Analytisches Erzählen und Kriminalschema 152

\section{Friedrich Schiller: Die gefährlichen Wunden der Vorsehung}

In den Babnen der Populärauflelärung . . . . . . . . . . . . . .

Der Spaziergang unter den Linden . . . . . . . . . . . . . . .

Voraussetzungen und Figuren 159 - Philosophie des Todes in Natur und Geschichte 160 - Die Leistung komischer Szenen 165 - Vom Schicksal der Seele - der psycho-physische Kompromiß und seine radikale Kritik 172 - Populärphilosophische Selbstverteidigung und ihre Grenzen 180 - Auf der Suche nach Wahrheit oder die Relativität menschlicher Erkenntnis 182 - Verhindertes Lebensglück - eine philosophische Bildergeschichte 183 - Aufgeklärtes Revoltieren gegen Gott 191 - Unversöhnter Dualismus - die Kreisbewegung des Dialogs 195 - Der Spaziergang unter den Linden ein geschichtsphilosophisches Denkmal exemplarischen Scheirerns 199

Eine großmütige Handlung, aus der neusten Geschichte . . . . . . . . . . . . .

Literaturtheoretisches Proömium - Erzählen im Spannungsfeld von idealischer und wirklicher Welt 203 - Der Kampf der Pflicht und Empfindung 204 - Leistung und Grenzen des älteren Bruders 210 - Der Märtyrersieg des jüngeren Bruders 215 - Die Paradoxie der Schlußpointe und ihr geschichtlicher Sinn 220

ANMER KUngen $\ldots \ldots \ldots \ldots \ldots \ldots$

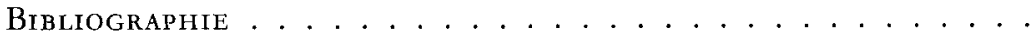

